\title{
Erratum
}

Diabetes Metab J 2021;45:283

https://doi.org/10.4093/dmj.2021.0026

pISSN 2233-6079 • eISSN 2233-6087

DIABET\&S \& METABOLISM JOURNAL

\section{Trends in Cardiovascular Complications and Mortality among Patients with Diabetes in South Korea}

\author{
Jung Hwan Park ${ }^{1}$, Kyoung Hwa Ha ${ }^{2,3}$, Bo Yeon Kim ${ }^{4}$ Jae Hyuk Lee ${ }^{5}$, Dae Jung Kim ${ }^{2,3}$ \\ ${ }^{1}$ Division of Endocrinology and Metabolism, Department of Internal Medicine, Hanyang University College of Medicine, Seoul, \\ ${ }^{2}$ Department of Endocrinology and Metabolism, ${ }^{3}$ Cardiovascular and Metabolic Disease Etiology Research Center, Ajou University School of \\ Medicine, Suwon, \\ ${ }^{4}$ Division of Endocrinology and Metabolism, Department of Internal Medicine, Soonchunhyang University Bucheon Hospital, Soonchunhyang \\ University College of Medicine, Bucheon, \\ ${ }^{5}$ Division of Endocrinology and Metabolism, Department of Internal Medicine, Myongii Hospital, Goyang, Korea
}

Diabetes Metab J 2021;45:120-124. https://doi.org/10.4093/dmj.2020.0175

An error was found in the following published article 'Trends in cardiovascular complications and mortality among patients with diabetes in South Korea' (Diabetes Metab J 2021;45(1):120-124). In brief report, there was a mistake in the legend for Fig. 2 published as an explanation of mortality rates among people with diabetes in South Korea in the period 2007 to 2015. A corrected version of Fig. 2 is attached.

Corrected Fig. 2.
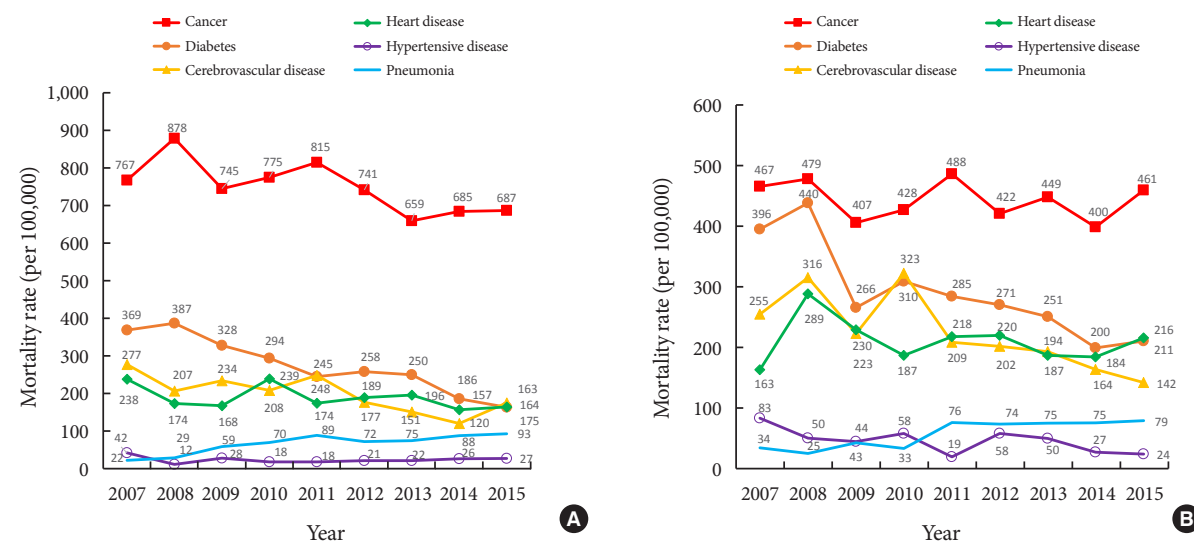

Fig. 2. Mortality rates among men (A) and women (B) with diabetes in South Korea (2007 to 2015).

This Fig. 2 has been corrected in the online version. We apologize for any inconvenience that this may have caused.

This is an Open Access article distributed under the terms of the Creative Commons Attribution Non-Commercial License (https://creativecommons.org/licenses/by-nc/4.0/) which permits unrestricted non-commercial use, distribution, and reproduction in any medium, provided the original work is properly cited. 